\title{
Thermal gradient of in-flight polymer particles during cold spraying
}

\author{
C.A. Bernard ${ }^{a, b}$, H. Takanac, G. Diguet ${ }^{b}$, K. Ravi ${ }^{\text {b,d }}$, O. Lame ${ }^{\text {e }}$, K. Ogawa ${ }^{\text {b,d }}$, J.-Y. Cavailléb \\ aFrontier Research Institute for Interdisciplinary Sciences, Tohoku University, Sendai, Japan \\ bELyTMaX UMI3757, CNRS-Université de Lyon-Tohoku University, International Joint Unit, \\ Tohoku University, Sendai, Japan \\ Institute of Fluid Sciences, Tohoku University, Sendai, Japan \\ ${ }^{\mathrm{d}}$ Fracture and Reliability Research Institute, Tohoku University, Sendai, Japan \\ eMaterials Engineering and Science (MATEIS), CNRS, INSA-Lyon, UMR5510, Université de \\ Lyon, Villeurbanne, France
}

*Corresponding author: chrystelle.bernard@rift.mech.tohoku.ac.jp

\begin{abstract}
The manufacture of polymer coatings via the cold-spray process remains challenging owing to the viscoelastic-viscoplastic behavior exhibited by polymers. One crucial step to improve cold-spray polymer coating is to determine the particles' thermal history during their flight from inside the nozzle to their impact on the substrate. In this study, we propose estimating the velocity and temperature of an isolated polymer particle traveling through a nozzle with a sharp change in its cross-section. The preliminary results show that the geometric discontinuity constricts the flow, thereby increasing the particle velocity. Moreover, a significant thermal gradient is expected inside the particle, which in turn leads to a gradient of mechanical properties of the polymeric particle during impact.
\end{abstract}

\section{Keywords}

Cold spray; Fluid dynamics; Polymer; Thermal gradient; Particle velocity

\section{Introduction}

Developed in the mid-1980s by the Institute of Theoretical and Applied Mechanics of the Russian Academy of Science in Novosibirsk (Alkhimov et al., 1990), the cold-spray process forms a coating on a substrate, using a powder with particle sizes from 1 to $100 \mu \mathrm{m}$ in diameter. The powder is carried by gas flow, which is accelerated through a de Laval nozzle. The process uses the plastic deformation of the particles and/or the substrate to build a coating. First developed for metallic materials, cold-spray technology has been recently extended to polymers, particularly ultra-high-molecular-weight polyethylene (UHMWPE) by Ravi et al. (2015). Although they were able to obtain a coating by adding $4 \%$ nano-alumina particles (Ravi et al., 2016), the deposition efficiency was quite low and needed improvement. Bush et al. (2017) highlighted that the critical velocity allowing the deposition of polymeric particles onto substrates is highly sensitive to the particles' temperature. In fact, the deposition efficiency is determined by the balance between the incident kinetic energy of the particles, their energy of adhesion, and the energy dissipated during their plastic deformation during impact. In the works of Ravi et al. (2016) and Sulen et al. (2019), the deposition of the polymer powder was only achieved thanks to the addition of the fumed-nano alumina ceramics to the feedstock. Thus, the coating built-up was only possible by the chemical interactions between the nano-ceramics surrounding the polymer particle and the metallic substrate. 
UHMWPE has been selected for its very interesting properties; however, these properties arise from its strong viscoelastic behavior. More precisely, UHMWPE exhibits excellent wear and impact resistance, and, for example, can effectively protect against the erosion of metallic structures during hydrodynamic cavitation (Deplancke et al., 2015a). However, it is difficult to process, mainly owing to its viscoelastic behavior, even at high temperatures (limited to its degradation). Thus, the low deposition efficiency of UHMWPE onto Al substrates can be explained partially by the thermomechanical behavior of the particles, as well as their weak adhesion.

UHMWPE is a semicrystalline polymer, and as such, exhibits two main microstructures, crystalline lamellae and amorphous domains, which are strongly linked to each other. The glass transition temperature of the polyethylene is well below $0^{\circ} \mathrm{C}$ (Popli et al., 1984). Thus, above room temperature, the amorphous domains are in a rubbery state. With a molecular weight of $10.5 \mathrm{Mg} \mathrm{mol}^{-1}$, the UHMWPE nascent powder investigated by Ravi et al. (2015) comprises very long macromolecular chains that participate in both the crystalline lamellae and amorphous domains (Deplancke et al., 2014, 2015b). Moreover, like other polymers, UHMWPE is also highly sensitive to the temperature and strain rate (Brown et al., 2007). Two mechanical relaxations, corresponding to a significant drop in the material stiffness and change of its microstructure, must be carefully identified. The first relaxation is related to the glass-rubber transition temperature $\mathrm{T}_{\mathrm{g}}$ of the amorphous domains, and is denoted $\mathrm{T}_{\alpha}$; this relaxation corresponds to complex motions of the main chain and is estimated to occur near $T_{\alpha}=-110^{\circ} \mathrm{C}$ for the studied UHMWPE (Nitta and Takayanagi, 1999). Above $T_{\mathrm{g}}$, the amorphous phase, crosslinked by the crystalline lamellae, behave like rubbery materials and therefore exhibit hyperelastic behavior. The second major drop in stiffness corresponds to the crystalline lamellae melting. It is characterized by their melting temperature $T_{m}$, which is approximately $135^{\circ} \mathrm{C}$ (Ravi et al., 2015). Between the glass transition temperature and the melting temperature, UHMWPE exhibits elastic-viscoelastic-viscoplastic behavior. This broad temperature range is of prime interest to the cold-spray process.

It is worth noting that the UHMWPE powder used for cold spray is nascent, i.e., it is used directly after production by the polymerization reactor. The nascent powder exhibits specific properties owing to its high crystallinity. However, according to Jauffrès et al. (2008), the thermomechanical behavior of nascent UHMWPE is not significantly different from meltcrystallized UHMWPE. It is true that the strain rate achieve in tensile tests are quite different that the one reached during cold-spray, however, for the present study, the specific mechanical properties of the powder particles are not of importance.

During their flight inside the nozzle, the particles are carried by the preheated and pressurized gas. Thus, under the influence of the gas temperature and pressure, particles undergo thermal gradients and sharp accelerations that need to be considered to better understand and improve the process. Thus, combining (i) the knowledge of the temperature and velocity of the particles before their impact on the substrate (this work) with (ii) the model of the thermomechanical behavior of UHMWPE (Bernard et al., 2018) will allow the improvement of the impact simulations performed to represent the cold-spray process.

Several studies focused on the gas dynamics inside the nozzle. Samareh and Dolatabadi (2007) investigated the optimal position of the substrate to minimized stagnation pressure during cold-spraying. It appears that the standoff distance is an essential cold spray parameter depending on the substrate surface (concave/convex) and inlet operating 
conditions. Schmidt et al. (2009) thoroughly investigated the flow dynamics and the particles' bonding mechanisms during cold spraying. They demonstrated that the particles' velocity at the nozzle exit is linked to the nozzle shape as well as the particle size. Thus, in the streamflow, small particles travel faster than bigger ones. Therefore, they can estimate the optimal spray parameters to reach the critical velocity of the particles and improve the adhesion of the metallic particles. Dykhuizen and Smith (1998) developed analytical equations to predict the particles' velocity in the gas, assuming the flow to be one-dimensional isentropic. Thus, they show from an analytical perspective that the particles' velocity is sensitive to the gas properties (nature of the gas, temperature, and pressure) and the size and density of the particles. Moreover, they also highlighted that the shape of the nozzle does not influence the particles' velocity. Takana et al. $(2010,2008)$ developed the numerical model considering the compressible flow and particle deposition. In their model, the coating profiles are also discussed as well as particle in-flight behavior in supersonic flow with shockwave.

However, most of these studies were performed for metallic particles, which need a short nozzle and higher pressure and temperature than polymers. Few researchers have focused on polymer particles' impact during cold spraying. Among them, Alhulaifi et al. (2012) investigated the influence of the convergent-divergent nozzle shape and length on the history of the particle inside the nozzle. Thus, a long nozzle makes it possible to increase the temperature of the particles but also reduces the particles' velocity before they exit the nozzle. This is true only if the inner part of the nozzle does not present any asperities, such as steps. The nozzle developed by Ravi et al. (2015) exhibits a sharp change in the cross-section, which contributes to the perturbation in the flow field (compared to the nozzle developed by Alhulaifi et al. (2012)). It aims to decrease the speed and increase the temperature of the particles to improve the polymer coating.

Moreover, unlike for metallic particles, the notion of critical velocity does not seem appropriate for polymer particles. As mentioned previously, polymers are strain rate and temperature-dependent, and UHMWPE is no exception. Thus, a successful deposition of polymeric particles on different substrates mainly depends on the temperature and velocity of the particles, as illustrated by Bush et al. (2017). For different substrates, they develop a map of successful deposition of high-density polyethylene particles while focusing on the particles' temperature and velocity, substrate temperature, and nozzle temperature. As mentioned above, for polymeric particles to stick to the substrate, equilibrium must be reached between the kinetic, adhesive, and rebound energies. Such conditions are difficult to achieve and mainly consist of achieving low velocity and high temperature of the particles (i.e., just below $T_{m}$ ), to minimize the rebound energy. Therefore, the length of the nozzle is also an aspect to consider when manufacturing polymer coating by cold spraying (Ravi et al., 2015).

A better understanding of the behavior of the particles during the entire process can be achieved by using a three-step approach. This approach consists of (i) defining the polymer behavior (Bernard et al., 2018) to predict the large deformation mechanisms of the polymeric particles, (ii) simulating the impact of the particles against the substrate to evaluate the particles' adhesion at the molecular scale, and (iii) understanding the gas dynamics inside the nozzle in the presence of the particles to assess its influence on the particles' thermal history. This last step is the objective of the present study. In this paper, parametric studies regarding gas temperature and pressure on the evolution of the polymer particles' thermal history along the nozzle are presented. 


\section{Modeling}

\subsection{Nozzle geometry}

The cold-spray system investigated in this study is the one used by Ravi et al. (2015, 2016). The standoff distance between the nozzle exit and the substrate is $10 \mathrm{~mm}$. The nozzle designed by Ravi et al. (2015) was simulated using Ansys/FLUENT ${ }^{\circledR} 19.0$ CFD software and is schematically reproduced in Figure 1. The entire nozzle is $259 \mathrm{~mm}$ long and is composed of a convergent-divergent section $19 \mathrm{~mm}$ in length and with two attached $120-\mathrm{mm}$-long diverging nozzles ${ }^{1}$. The diameters for the inlet, throat, and outlet of the convergent-divergent section are $4.4 \mathrm{~mm}, 2.2 \mathrm{~mm}$, and $3.2 \mathrm{~mm}$, respectively. The cross-sections of both of the $120 \mathrm{~mm}$ nozzle sections are $4 \mathrm{~mm}$ in diameter at the inlet and $5 \mathrm{~mm}$ in diameter at the outlet. Thus, steps in the inner nozzle geometry exist between the convergent-divergent section and the first nozzle section and between the first and the second nozzle section. In the following, we denote the first and second sections of the nozzle as "first nozzle" and "second nozzle," where "nozzle" refers to the whole nozzle composed of the converging-diverging section, first nozzle section, and second nozzle section.

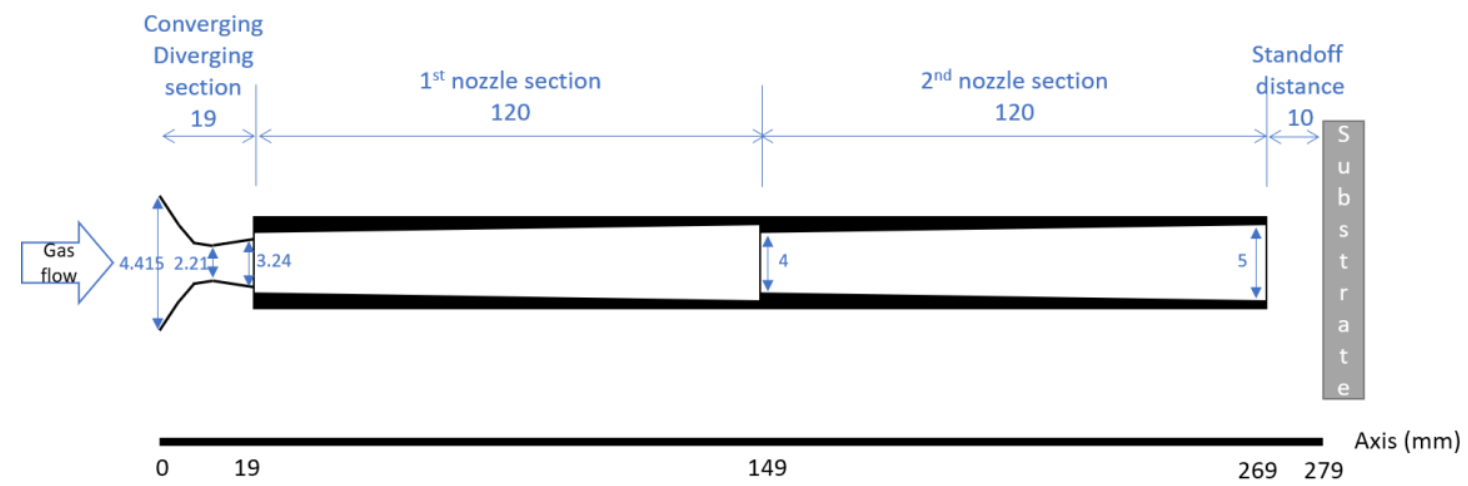

Figure 1: Schematic reproduction of the nozzle designed by Ravi et al. (2015) for the cold-spray of UHMWPE. TWO $120 \mathrm{~mm}$ diverging nozzles were fitted. All dimensions are given in $\mathrm{mm}$.

In the absence of the powder feeder, the entire nozzle exhibits axisymmetric geometry, as does the flow if we consider the particle phase well-diluted in the gas flow (the particles are assumed not to perturb the gas flow in the nozzle). Thus, an axisymmetric model has been developed to measure the evolution of the flow field inside the nozzle. This model was also used to evaluate the particles' velocity, temperature, and trajectory before impact. Parametric studies regarding the gas temperature and pressure were also performed to improve our comprehension of the influence of the gas on the state of one particle.

We used inflation layer, consisting in element stacking in the normal direction to the boundary, to capture the discontinuity linked to the boundary layers, bow shocks, and expansion waves. ANSYS mesh inflation introduces finer meshes on the edges of the nozzle and on the substrate with 10 layers and 5 layers, respectively. A quadrilateral mesh was chosen to calculate the gas flow consisting of 149667 elements for the 2D axisymmetric nozzle.

\footnotetext{
${ }^{1}$ Ravi et al. $(2015,2016,2018)$ utilized a nozzle length of $200 \mathrm{~mm}$ to have a rough evaluation of the particle temperature and velocity using an analytical model. In the present work, based on numerical analysis, the precise nozzle dimensions $(2 * 120 \mathrm{~mm})$ was taken into account, obtained after nozzle measurement and in agreement with Dr. Ravi, also co-author of this paper.
} 


\subsection{Gas flow field}

The following assumptions were used to derive the constitutive equations needed for the computation of the flow field:

- The flow is compressible and turbulent.

- The working gas is air, and the gas species inside and outside the nozzle are the same.

- The conditions on the nozzle's wall and substrate are adiabatic.

Reynolds-averaging computation was performed to avoid simulating small-scale turbulent fluctuations. Under these assumptions, the velocity and governing equations for the flow field are described as follows:

- Continuity equation

$$
\frac{\partial \rho}{\partial t}+\nabla \cdot(\rho \boldsymbol{u})=0
$$

- Momentum equation

$$
\frac{\partial(\rho \boldsymbol{u})}{\partial t}+\nabla \cdot(\rho \boldsymbol{u} \boldsymbol{u})=-\nabla p+\nabla \cdot \tau_{i j}
$$

- Energy equation

$$
\frac{\partial\left(\rho E_{s}\right)}{\partial t}+\nabla \cdot\left(E_{s} \boldsymbol{u}\right)=-\nabla \cdot\left(\Pi_{i j} \cdot \boldsymbol{u}\right)-\nabla \cdot \boldsymbol{q}
$$

where $\rho$ is the gas density, $p$ is the gas pressure, $\partial t$ represents the time derivative, $\boldsymbol{u}$ is the flow velocity, $\tau_{j}$ is the viscous stress tensor, $E_{s}$ is the total internal energy, $\Pi_{i j}$ is the stress tensor, and $\boldsymbol{q}$ is the heat flux. The realizable $k-\varepsilon$ model is used to simulate the turbulent flow. The turbulent viscosity $\mu_{t}$ is given by $\mu_{t}=\frac{C_{\mu} \rho k^{2}}{\varepsilon}$, where $C_{\mu}$ is a constant, $k$ is the turbulent energy, and $\varepsilon$ is the rate of dissipation. The turbulent energy $k$ and dissipation rate $\varepsilon$ are obtained by solving the following equations (ANSYS, Inc., 2017):

$$
\left\{\begin{array}{l}
\frac{\partial(\rho k)}{\partial t}+\nabla \cdot(\rho k \boldsymbol{u})=\nabla \cdot\left[\left(\mu+\frac{\mu_{t}}{P r_{k}}\right) \nabla k\right]+G_{k}+G_{b}-\rho \varepsilon-Y_{M} \\
\frac{\partial(\rho \varepsilon)}{\partial t}+\nabla \cdot(\rho \varepsilon \boldsymbol{u})=\nabla \cdot\left[\left(\mu+\frac{\mu_{t}}{P r_{\varepsilon}}\right) \nabla \varepsilon\right]+\rho C_{1} S \varepsilon-1.9 \rho \frac{\varepsilon^{2}}{k+\sqrt{v \varepsilon}}+1.44 \frac{\varepsilon}{k} C_{\varepsilon} G_{b}
\end{array}\right.
$$

where $\mu$ and $v$ are the flow molecular viscosity and flow kinetic viscosity, respectively. $G_{k}$ and $G_{b}$ represent the generation of turbulence kinetic energy due to the mean velocity gradients and buoyancy, respectively. $Y_{M}$ represents the contribution of the fluctuating dilatation in compressible turbulence to the overall dissipation rate, $S$ is the magnitude of mean strain rate, $C_{\varepsilon}$ is a constant, and $C_{1}$ is a parameter depending on $k, \varepsilon$ and the deformation tensor. $\operatorname{Pr}_{k}$ and $\operatorname{Pr}_{\varepsilon}$ are turbulent Prandtl numbers for $k$ and $\varepsilon$, and respectively equal to 1 and 1.2.

To solve these equations, we used a transient step time combined with an implicit solver coupled with a first-order discretization scheme.

One significant dimensionless number used to characterize the regime of the flow is the Mach number. It is defined as the ratio of the flow velocity $\boldsymbol{u}$ to the speed of the sound of the working gas. In our case, the working gas is air, and the sound speed in air is denoted 
as $c_{\text {air }}$. The Mach number $\mathcal{M}_{a}$ is temperature-dependent through the sound speed and follows the following equation:

$$
\mathcal{M}_{a}=\frac{\boldsymbol{u}}{c_{\text {air }}} \text { with } c_{\text {air }}=\sqrt{\gamma R_{\text {air }} T}
$$

where $\gamma$ is the ratio of the specific heat (1.4 for the air), $R_{\text {air }}$ is the specific gas constant (around $287 \mathrm{~m}^{2} \mathrm{~s}^{-2} \mathrm{~K}^{-1}$ for the air), and $T$ is the absolute temperature of the fluid.

\subsection{Particle-fluid interaction}

The investigation on the trajectory of the particle was performed using the Discrete Phase toolbox of FLUENT with the Lagrangian framework. Particles are injected into the nozzle at a distance of $18 \mathrm{~mm}$ from the inlet on the symmetry axis with no velocity at $300 \mathrm{~K}$. This distance is located in a region corresponding to the end of the throat and the beginning of the convergent-divergent nozzle.

To determine the particles' trajectory, the equation of motions are solved involving terms of gravity $\boldsymbol{F}_{\text {grav }}$, viscous drag force $\boldsymbol{F}_{\text {drag }}$, flow acceleration $\boldsymbol{F}_{\text {acc }}$, thermophoretic force $\boldsymbol{F}_{\text {therm }}$, Saffman Lift force $\boldsymbol{F}_{\text {Saff }}$, and pressure gradient force $\boldsymbol{F}_{\text {Press }}$

$$
\begin{gathered}
m_{p} \frac{d \boldsymbol{u}_{p}}{d t}=\boldsymbol{F}_{g r a v}+\boldsymbol{F}_{d r a g}+\boldsymbol{F}_{a c c}+\boldsymbol{F}_{\text {therm }}+\boldsymbol{F}_{\text {saff }}+\boldsymbol{F}_{\text {Press }} \\
\frac{d \boldsymbol{x}_{p}}{d t}=\boldsymbol{u}_{p}
\end{gathered}
$$

with the subscript " $p$ " referring to the particle.

The viscous drag force is expressed as

$$
\boldsymbol{F}_{\text {drag }}=\frac{\pi}{2} d_{p}^{2} \rho C_{D}\left(\boldsymbol{u}-\boldsymbol{u}_{p}\right)\left|\boldsymbol{u}-\boldsymbol{u}_{p}\right|
$$

where $d_{p}$ is the particle diameter and $C_{D}$ is the drag coefficient, a dimensionless number, defined for a spherical particle by the relation of Morsi and Alexander (Morsi and Alexander, 1972).

The thermophoresis characterizes the phenomenon of fine particles or molecules suspended in a gas and submitted to a significant thermal gradient. Under the temperature effect, the hot particles/molecules exert an attractive/repulsive force on colder particles/molecules. It is called the thermophoretic force and is expressed as

$$
\boldsymbol{F}_{\text {therm }}=-\frac{6 \pi d_{p} \mu^{2}}{\rho m_{p}} \frac{1.17\left(K+2.18 K_{n}\right)}{\left(1+3.42 K_{n}\right)\left(1+2 K+4.36 K_{n}\right)} \frac{\nabla T}{T}
$$

where $m_{p}$ is the particle mass, $K$ is the ratio of thermal conductivity between the gas and the particle, and $K_{n}$ is the Knudsen number. Unlike drag force, the intensity of the thermophoretic force remains low. 
In the first and second nozzles, the particles can also experience lift forces. The force, which originates from the inertial effect, is perpendicular to the flow direction and induces shear to the particles. It is expressed using Saffman's lift force (Saffman, 1965):

$$
\boldsymbol{F}_{\text {Saff }}=\frac{5.188 v^{1 / 2} \rho}{\rho_{p} d_{p}} \frac{\mathbb{D}}{(\mathbb{D}: \mathbb{D})^{1 / 4}}\left(\boldsymbol{u}-\boldsymbol{u}_{p}\right)
$$

where $\mathbb{D}$ is the deformation gradient.

Under the gas influence, the particles will heat up and accelerate. As the particles' trajectory is calculated, the average particle temperature $\left\langle T_{p}\right\rangle$ is determined at each time step as

$$
m_{p} c_{p} \frac{d\left\langle T_{p}\right\rangle}{d t}=h A_{p}\left(T_{\infty}-\left\langle T_{p}\right\rangle\right)
$$

where $c_{p}$ and $A_{p}$ are the heat capacity and surface area of the particles, respectively. $h$ is the convective heat transfer coefficient, and $T_{\infty}$ represents the local gas temperature.

\subsection{Boundary and initial conditions}

Figure 2 schematically exhibits the boundary conditions. The pressure and stagnation temperature were introduced as initial conditions at the inlet, and we considered the adiabatic conditions on the nozzle wall and substrate (no-slip wall). Parametric studies regarding pressure and stagnation temperature were carried out to investigate their influence on the particles' history inside the first and second nozzles. The open boundaries refer to the back-region domain boundaries and consider atmospheric pressure and room temperature $(300 \mathrm{~K})$ conditions. The initial temperature of the substrate, as well as the particles' temperature at its introduction inside the nozzle, was set to $300 \mathrm{~K}$. One particle was injected at $0 \mathrm{~m} \mathrm{~s}^{-1}$ in the axial direction and $27 \mathrm{~mm}$ from the gas inlet, at the end of the convergentdivergent section on the axisymmetric axis. Because of the gas and the geometry of the nozzle, the particle accelerates before impacting the substrate. The particle-tracking toolbox from Fluent is used to follow the single-particle traveling inside the nozzle.

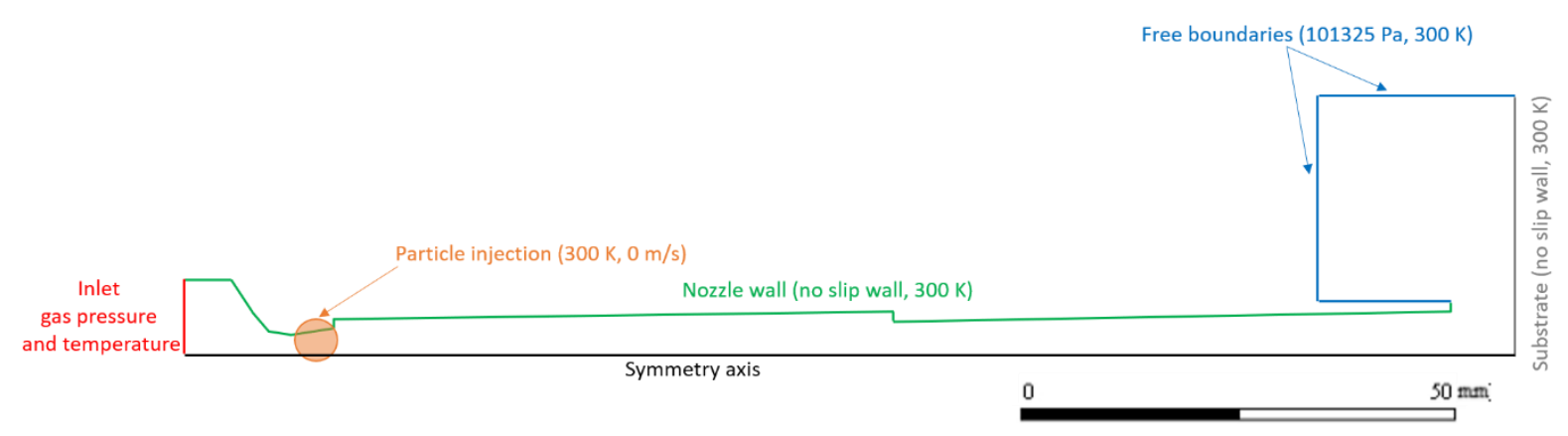

Figure 2: Boundary conditions of the studied cold-spray system.

Table 1 summarizes the computational and boundary conditions for the gas. These conditions reflect the range of applicability of the low-pressure cold-spray used in the experiment of Ravi et al. (2018). Table 2 presents the thermal and geometric conditions of the polymeric particles. 
Table 1: Computational conditions for the cold-spray system model.

\begin{tabular}{ll}
\hline Working gas & Air \\
Inlet gas temperature & $293-773 \mathrm{~K}$ \\
Inlet gas pressure & $0.2-0.6 \mathrm{MPa}$ \\
Ambient gas pressure & $0.1013 \mathrm{MPa}$ (atmospheric pressure) \\
Ambient gas temperature & $300 \mathrm{~K}$ (room temperature) \\
Nozzle material & Stainless steel \\
Substrate material & Aluminum \\
\hline Table 2: Mechanical and geometric properties of the polymer particle. These values are slightly different from \\
those of the nascent powder, which are difficult to obtain. \\
\hline Particle material & $\mathrm{UHMWPE}$ \\
\hline Particle density $\rho_{p}$ & $940 \mathrm{~kg} \mathrm{~m}^{-3}$ \\
Particle specific heat $c_{p}$ & $2220 \mathrm{~J} \mathrm{~kg}^{-1} \mathrm{~K}^{-1}$ \\
Particle thermal conductivity $\Gamma$ & $0.41 \mathrm{~W} \mathrm{~m}^{-1} \mathrm{~K}^{-1}$ \\
Particle diameter & $60-300 \mu \mathrm{m}$ \\
Particle initial velocity & $0 \mathrm{~m} \mathrm{~s}^{-1}$ \\
\hline
\end{tabular}

\section{Results and Discussion}

\subsection{Flow field}

We investigated the influence of both the inlet gas pressure and gas temperature for the gas flow field alone (without particle). This allows a better understanding of the importance of the steps inside the nozzle. The following figures are all plotted along the symmetry axis of the nozzle.

In Figure 3, the contour of Mach number is plotted for the studied nozzle. The initial conditions for the nozzle are taken to be the optimal conditions to obtain a polymer coating, according to Ravi et al. (2015) (pressure $0.4 \mathrm{MPa}$, temperature $653 \mathrm{~K}$ ). The convergentdivergent section exhibits a Mach number equal to 1 . Because of the expansion of the nozzle section, a series of shockwaves appears at the beginning of the first nozzle, decelerating the supersonic flow to subsonic flow. The Mach number reaches 2.32 before decreasing to approximately 0.35 at the end of the first nozzle. At the connection of the two nozzles, the flow chokes again due to the decrease in the cross-section size (the nozzle section decreases by $20 \%$ ). Thus, the flow accelerates once again (up to a Mach number of approximately 0.70 ) before exiting the nozzle and reaching the substrate. It is noteworthy that the plate shock wave appears in the impinging supersonic jet just in front of the substrate. 


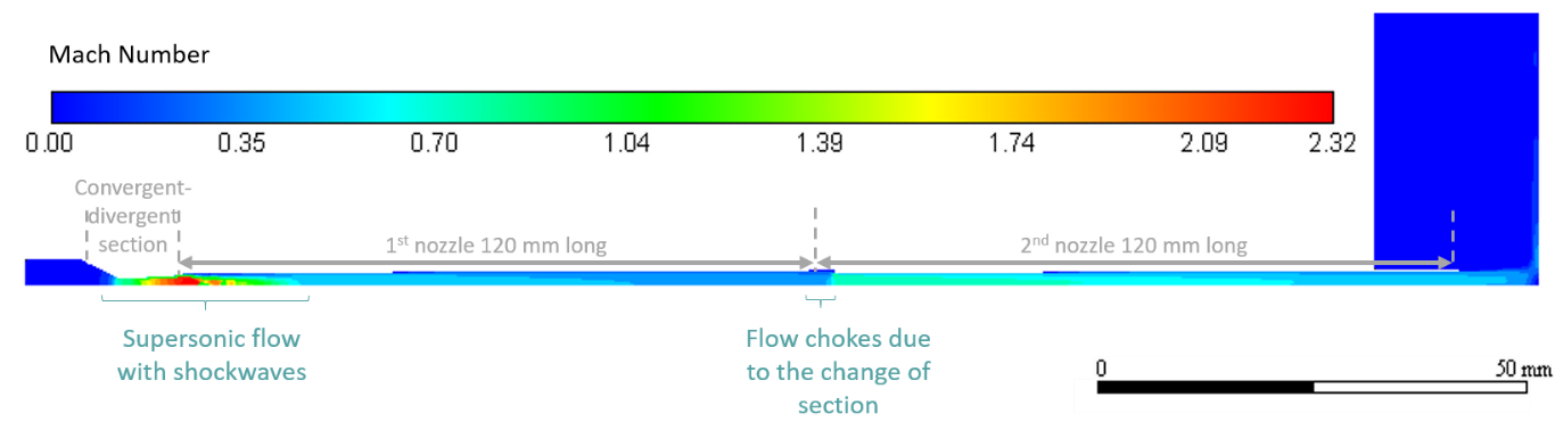

Figure 3: Mach number contour of the studied nozzle. The gas is injected at a pressure and temperature of $0.4 \mathrm{MPa}$ and $653 \mathrm{~K}$, respectively. These conditions correspond to the optimal processing parameters allowing a coating to be obtained (Ravi et al., 2015).

In the following section, we investigate the influence of the inlet gas temperature (Figure 4) and inlet gas pressure (Figure 5) on the flow-field behavior along the nozzle axis. Figure 4 exhibits the flow-field changes for five different inlet gas temperatures, ranging from $293 \mathrm{~K}$ to $773 \mathrm{~K}$. We observe a drop in gas temperature (Figure 4a) and gas pressure (Figure 4b) at the convergent-divergent section, independently of the inlet gas temperature. On the contrary, we observe that increasing the Mach number (Figure 4c) and gas velocity (Figure $4 d)$ leads to supersonic flow. Fluctuations due to the presence of a series of shockwaves are observed at the beginning of the first nozzle. They are followed by stabilization of the flow parameters (temperature, pressure, Mach number, velocity) until the end of the first nozzle. At the beginning of the second nozzle, decreases in the gas temperature and gas pressure are observed when the Mach number and gas velocity increase because the flow is choked once again inside the nozzle due to the decrease in the nozzle section. Along the second nozzle, the gas temperature and gas pressure increase slightly while the Mach number and the gas velocity are decreasing. Depending on the gas-inlet temperature, along the second nozzle, the gas velocity decreases by $100 \mathrm{~m} \mathrm{~s}^{-1}$ or even $160 \mathrm{~m} \mathrm{~s}^{-1}$ depending on the operating pressure.

The profile of the gas pressure (Figure 4b) and Mach number (Figure 4c) depends very little on the inlet gas temperature, and that only in the instability zones. In contrast, the inlet gas temperature changes the gas velocity (Figure $4 d$ ) along the nozzle axis. Thus, the inlet gas temperature modifies both the gas temperature and gas velocity profiles. 

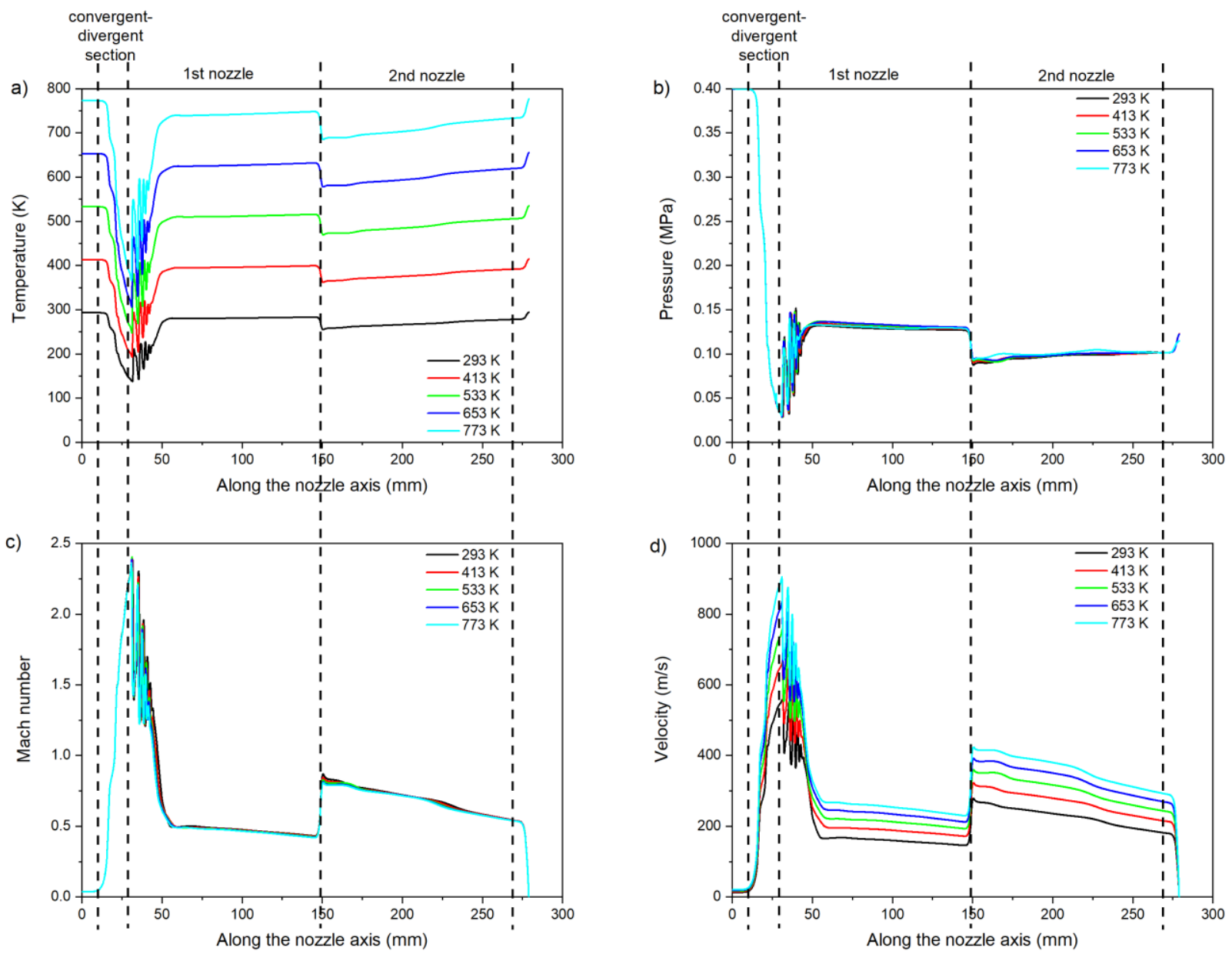

Figure 4: Influence of the inlet gas temperature on the a) gas temperature, b) gas pressure, c) Mach number, and d) gas velocity along the nozzle axis. The inlet gas pressure is set to $0.4 \mathrm{MPa}$.

Figure 5 exhibits the effect of the inlet gas pressure on the (i) gas pressure (Figure 5a), (ii) gas temperature (Figure 5b), (iii) Mach number (Figure $5 \mathrm{c}$ ), and (iv) gas velocity (Figure $5 \mathrm{~d}$ ). The inlet gas pressure ranges from 0.2 MPa to 0.6 MPa for an inlet gas temperature of $653 \mathrm{~K}$. The general behavior of the gas pressure, gas temperature, gas velocity, and Mach number along the nozzle axis is the same as that previously described. However, the inlet gas pressure, in this case, has a stronger influence on the gas flow behavior than the inlet gas temperature. First, for an inlet gas pressure of $0.2 \mathrm{MPa}$, shockwaves are observed. However, the length of the shockwaves is shorter than that for higher inlet gas pressure. Moreover, at the discontinuity between the two nozzles, even though the flow chokes, its acceleration only represents one-third of the acceleration observed for higher pressures (after the choke, the increase in velocity is around $70 \mathrm{~m} \mathrm{~s}^{-1}$ at $0.2 \mathrm{MPa}$ ).

From an inlet pressure of $0.3 \mathrm{MPa}$, series of shockwaves appear at the beginning of the first nozzle due to the increase in the nozzle section and the gradient of pressure inside the nozzle. At the discontinuity between the two nozzles, because of the decrease in the section and the pressure gradient inside the nozzle, the flow chokes, leading to acceleration of the flow. Thus, at the intersection between the two nozzles, the gas velocity is affected by the inlet pressure and increases in the range of $120 \mathrm{~m} \mathrm{~s}^{-1}$ to $205 \mathrm{~m} \mathrm{~s}^{-1}$. It generates a shockwave, which propagates inside the second nozzle. Shockwaves are observed inside the 
nozzle. We see a small drop in the Mach number and gas velocity and an increase in the gas temperature along the nozzle axis between $230 \mathrm{~mm}$ and $270 \mathrm{~mm}$.
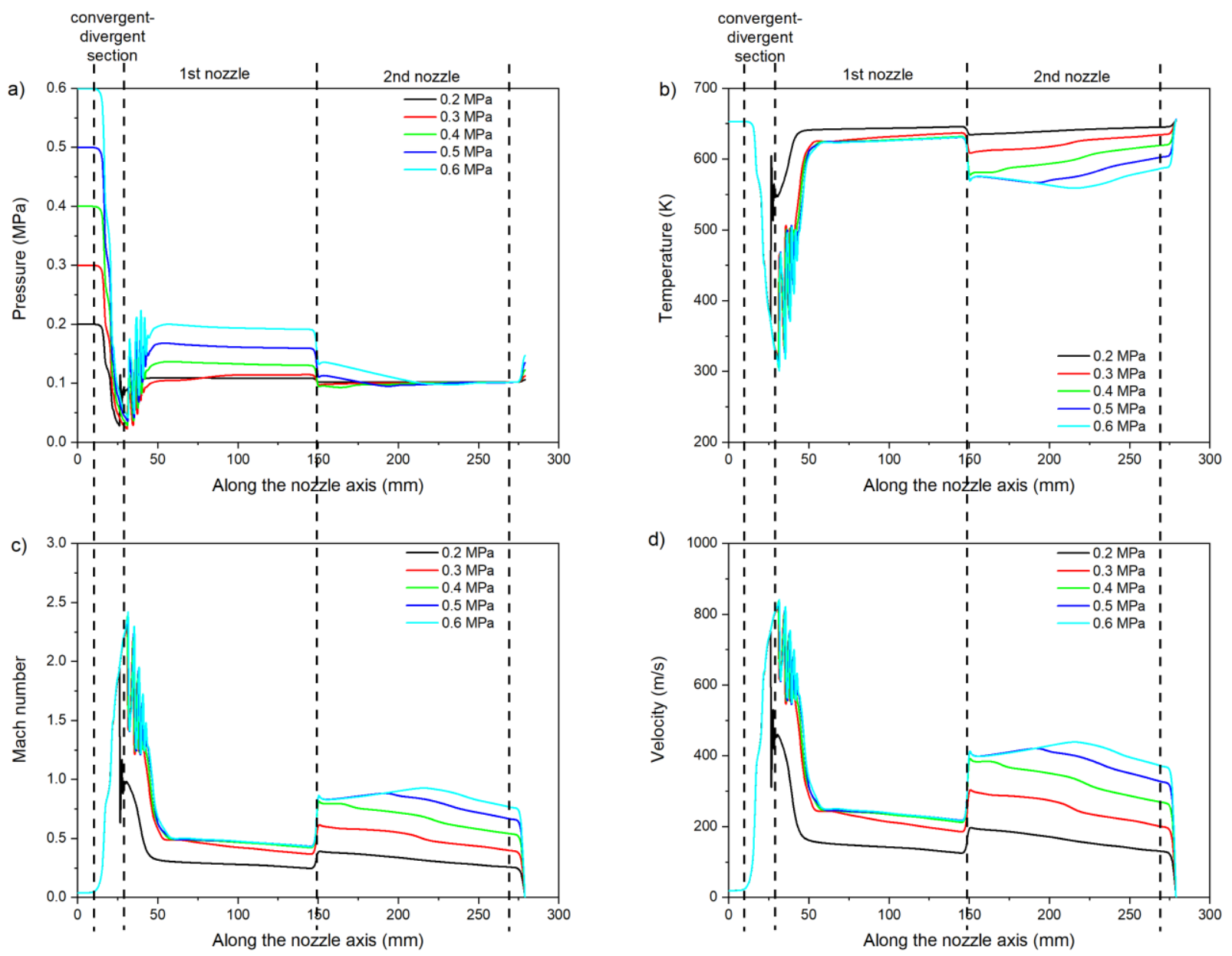

Figure 5: Influence of the inlet gas pressure on the a) gas pressure, b) gas temperature, c) Mach number, and d) gas velocity along the nozzle axis. The inlet gas temperature is set to $653 \mathrm{~K}$.

\subsection{Particle injection}

In this section, we investigate the velocity, temperature, and trajectory of a single polymeric particle corresponding to a diluted situation in the gas inside the nozzle (particles without interactions between each other). Thus, the above equations (Eqs.(1)-(4)) are still valid. As mentioned previously, a polymeric particle is injected at the end of the convergingdiverging section and just before the first nozzle. We investigated the effect of the inlet gas temperature (Figure 6) and pressure (Figure 7) on the particle temperature during its flight inside the nozzle. The influence of the particle diameter on its thermal history inside the nozzle was also investigated (Figure 8). Table 2 summarizes the particle thermal properties.

The effect of the inlet gas temperature on the particle's thermal and velocity history inside the nozzle is shown in Figure 6. If the inlet gas temperature is not high enough, the particle cools down during its journey inside the nozzle (Figure 6a, for $\mathrm{T}=293 \mathrm{~K}$ ). For higher gas temperatures, the particle's temperature increases almost linearly. Moreover, the particle's temperature increase can be quite high (around $60 \mathrm{~K}$ and $80 \mathrm{~K}$ for $653 \mathrm{~K}$ and $773 \mathrm{~K}$, respectively). For these conditions, the particle's temperature is close to its melting 
temperature. Thus, special attention should be given to the temperature gradient along the particle's radius.

However, the particle's velocity is more sensitive to the nozzle geometry than its temperature (Figure 6b). Just after its introduction inside the nozzle, the particle is subject to rapid acceleration. Thus, its velocity evolves from $0 \mathrm{~m} \mathrm{~s}^{-1}$ to approximately $150 \mathrm{~m} \mathrm{~s}^{-1}$ in a very short time and distance. After this first acceleration, the particle's velocity remains constant until it meets the second nozzle and then the flow chokes. It results in a second acceleration of the particle and an increase in its speed between 25 and $50 \mathrm{~m} \mathrm{~s}^{-1}$. In the function of the inlet gas temperature, for an inlet gas pressure of $0.4 \mathrm{MPa}$, the particle's velocity is ranged between 170 and $230 \mathrm{~m} \mathrm{~s}^{-1}$. The comparison of the numerical predictions with the experimental measurements performed by Ravi et al. (2018) shows good agreement for the two inlet gas temperatures ( $293 \mathrm{~K}$ and $653 \mathrm{~K}$ ).
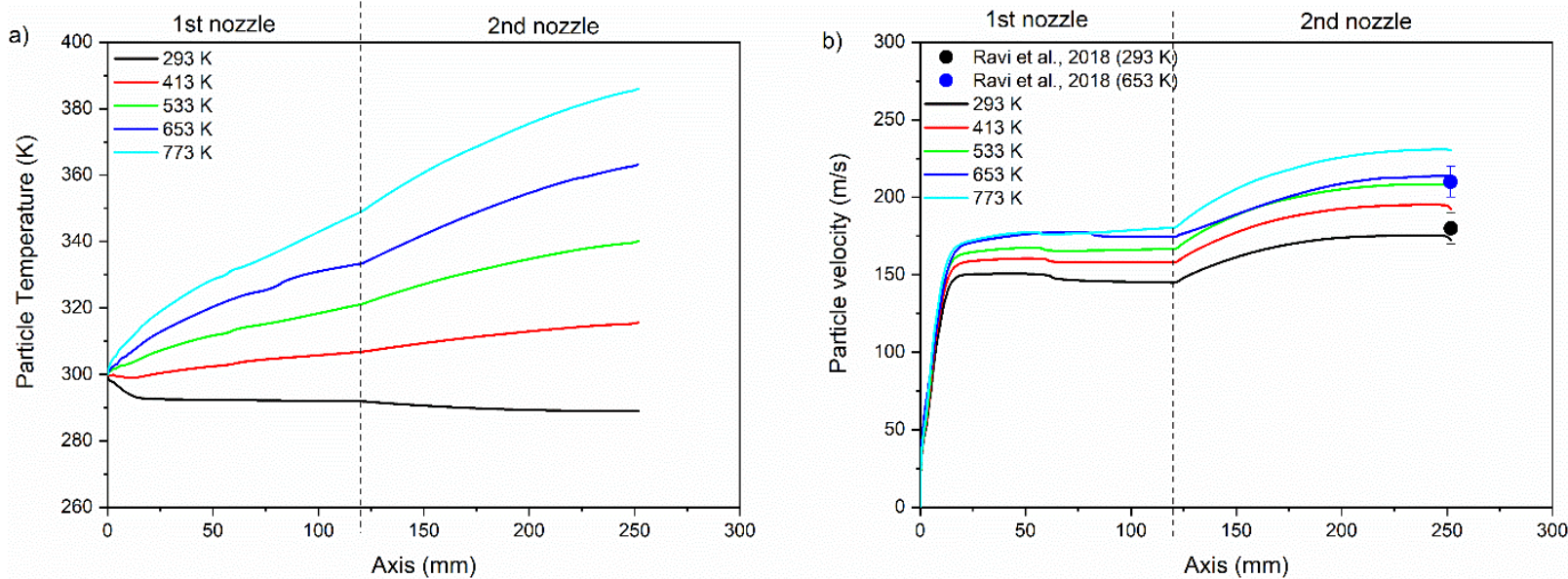

Figure 6: Influence of the inlet gas temperature on the particle history inside the nozzle. The particle diameter and inlet gas pressure are set to $60 \mu \mathrm{m}$ and $0.4 \mathrm{MPa}$, respectively. At the injection point, the particle temperature is $300 \mathrm{~K}$.

The influence of the inlet gas pressure on the particle's history inside the nozzle is plotted in Figure 7. Two main conclusions can be extracted from Figure 7. First, low gas pressure induces low particle velocity, which in turn contributes to the second, an increase in the particle's resident time inside the nozzle and thus its temperature. For an inlet gas pressure of $0.2 \mathrm{MPa}$, the introduction of the second nozzle with the step does not strongly influence either the particle temperature or velocity. At $0.2 \mathrm{MPa}$, the particle is only submitted to the first acceleration, owing to its injection at the inlet of the first nozzle, and its velocity remains quite constant until the end of its flight inside the nozzle. In contrast, at a higher inlet gas temperature, after its first acceleration due to its injection, the particle encounters a second acceleration due to the discontinuity between the first and the second nozzles. Around the middle of the second nozzle, the particle's velocity is stabilized owing to the presence of the shockwave inside the second nozzle. 

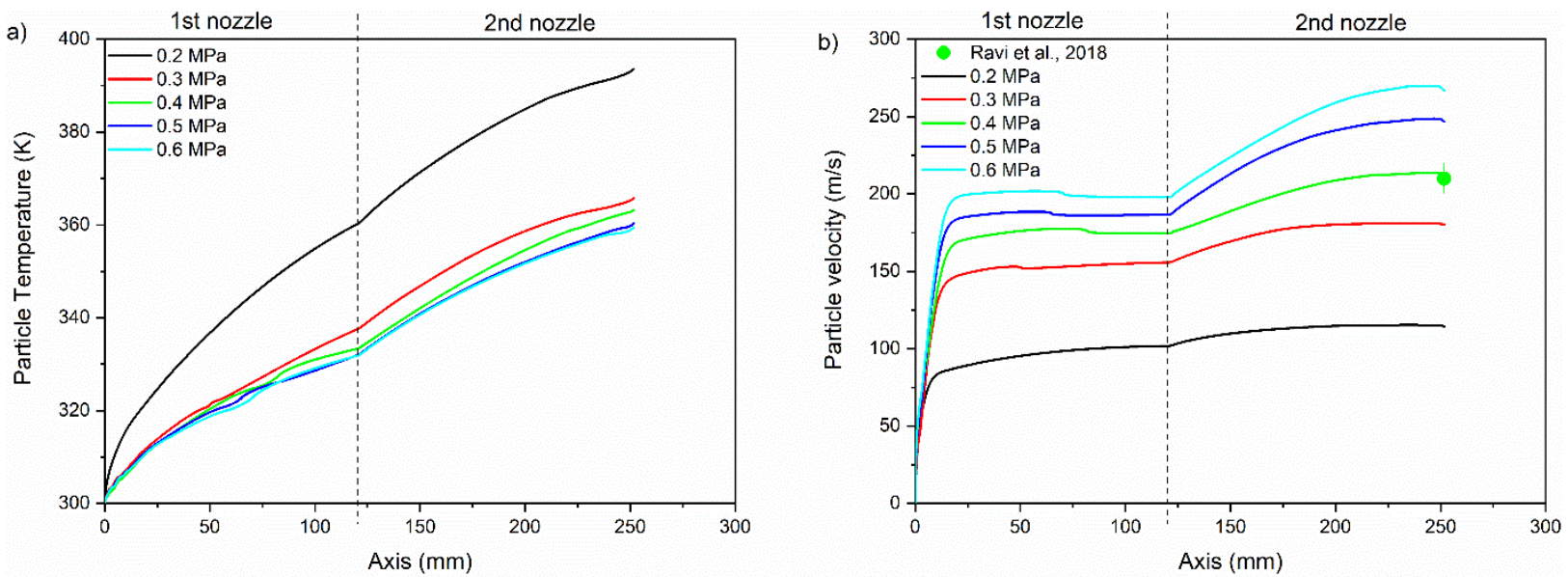

Figure 7: Effect of the inlet gas pressure on the particle history inside the first and second nozzle. The particle diameter and inlet gas temperature are set to $60 \mu \mathrm{m}$ and $653 \mathrm{~K}$. At the injection point, the particle temperature is $300 \mathrm{~K}$.

The effect of the particle's diameter on the particle's history inside the nozzle is also non-negligible. For particle diameters ranging from $60 \mu \mathrm{m}$ to $300 \mu \mathrm{m}$, the particle's temperature and velocity during its journey inside the nozzle are plotted in Figure 8. Because smaller particles can reach thermal equilibrium faster than bigger particles, the smaller the particle's diameter, the higher the average temperature (see Figure 8a). Through convection and conduction, particles slowly heat up during their flight. If, before impact on the substrate, the particles reach their thermal equilibrium, then regardless of their size, the average temperature must be the same and equal to the gas temperature. Because, as shown in Figure $8 \mathrm{a}$, the particle temperature depends on its diameter, a thermal gradient exists along the particle diameter. As the polymer's mechanical behavior is highly sensitive to heat, investigating the temperature map inside the particle is required to understand better the deformation mechanisms during cold spraying.

As illustrated in Figure $8 \mathrm{~b}$, because a larger particle is also heavier, its velocity is less than that of a smaller particle. Moreover, the effect of the discontinuity at the entrance of the second nozzle has even less consequence on the particle velocity (Figure $8 \mathrm{~b}$ ). Ravi et al. (2018) used a high-speed camera to measure the speed of the polymeric particles with diameters ranging from 45 to $63 \mu \mathrm{m}$. This velocity was estimated at $210 \mathrm{~m} \mathrm{~s}^{-1}$ for an inlet gas pressure of $0.4 \mathrm{MPa}$ and an inlet gas temperature of $653 \mathrm{~K}$. A good agreement is observed between the numerical predictions and the experimental results of Ravi et al. (2018).
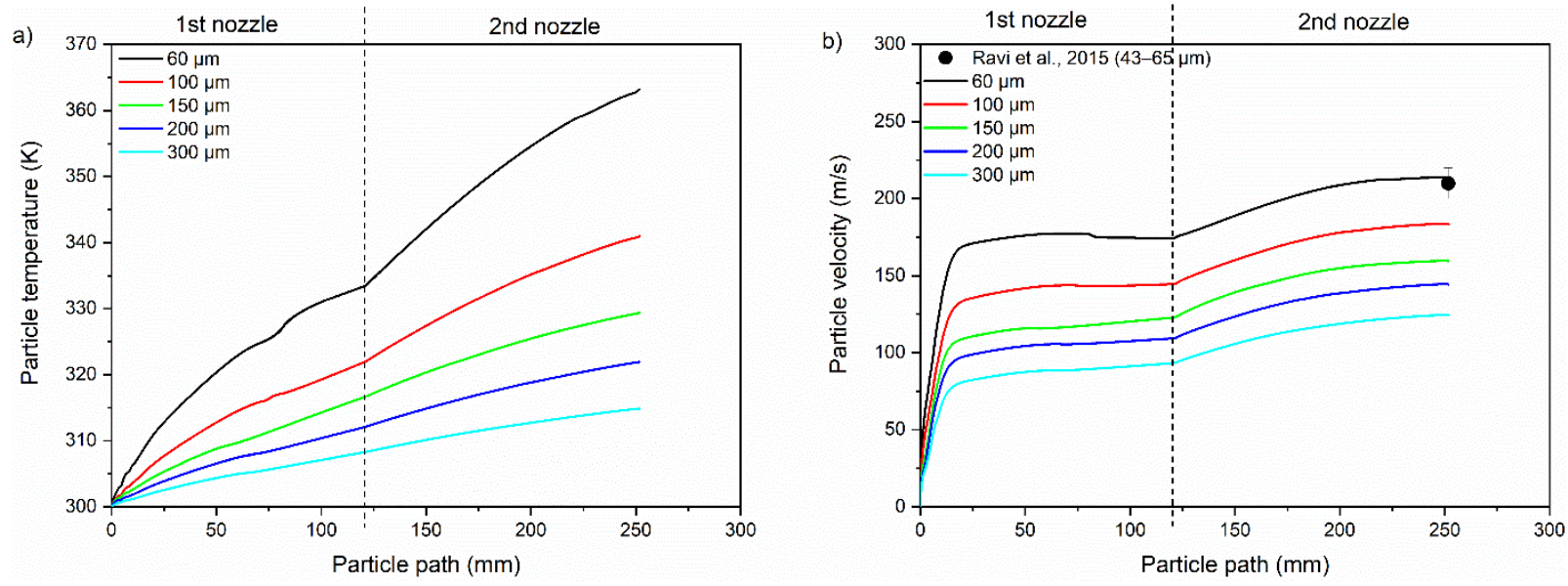
Figure 8: Influence of the particle diameter on the particle history inside the nozzle. The inlet gas temperature and inlet gas pressure are set to $653 \mathrm{~K}$ and $0.4 \mathrm{MPa}$, respectively. At the injection point, the particle is at $300 \mathrm{~K}$.

According to Figure $8 \mathrm{a}$, a noticeable temperature difference, of about $45 \mathrm{~K}$ between $60 \mu \mathrm{m}$ particle and $300 \mu \mathrm{m}$ particle, is observed between the different particle sizes obtained from the same inlet gas temperature and pressure. Such behavior allows us to assume the existence of a thermal gradient within the particle diameter. This assumption is based on the principle that if the particle was in thermal equilibrium, then regardless of the particle diameter, the temperature of the particle should be the same and equal to the gas temperature.

By considering the flow velocity and temperature shown in Figure 5 for the inlet conditions $0.4 \mathrm{MPa}-653 \mathrm{~K}$, a typical Biot number of 15 is obtained for a $60-\mu \mathrm{m}$ particle (Cohen, 1961) (the gas properties were taken at $600 \mathrm{~K}$, average gas temperature in the nozzle, from ("Engineering Toolbox, Dry Air Properties," n.d.)). As the Biot number is much larger than 1, a non-uniform temperature exists within the particle. In the case of polymers, a thermal gradient within the particle results in a gradient of mechanical properties. Thus, during the cold-spray process, because of the thermal gradient, the particle core and surface will behave differently. To understand the particle behavior, the first step is to establish the temperature profile of the particle just before impact on the substrate.

\subsection{Particle thermal history}

The particle temperature along the cold-spray nozzle is evaluated in this section. The purpose of this analysis is to study the thermal gradient of the particles from their injection point to the substrate. The analysis of a single particle's temperature profile was performed by the finite-element method using COMSOL Multiphysics 5.4 software. A 2D axisymmetric model was developed to investigate the temperature profile induced by contact of the particle with heated gas, as shown in Figure 9a. Moreover, as the particle is assumed to be spherical, the $x$-axis is a symmetry axis. Calculations were performed for particles with varying radius $r_{p}$ from $30 \mu \mathrm{m}$ to $150 \mu \mathrm{m}$.

The configuration considered here is composed of a polymer particle of radius $r_{p}$ surrounded by the gas, represented by a square box of length $=2 * r_{p}$, as shown in Figure $9 a$. The number of elements is independent of the problem size. Thus, it is fixed at 5373 elements for the particle and 3957 elements for the gas. The initial temperature of the particle is set to $300 \mathrm{~K}$. As shown in Figure 4a, the gas temperature depends on the nozzle position and inlet gas conditions. Moreover, according to Figure $8 \mathrm{~b}$, the resident time of the particle inside the nozzle, linked to the particle velocity, is highly sensitive to the particle size. To investigate the thermal particle history inside the nozzle, we only need the evolution of the gas temperature from the particle injection point. Thus, the temperature of the gas surrounding the particle is linked to the time according to the particle position, where the time $t=0 \mathrm{~s}$ corresponds to the particle injection point. In the following calculation, only the data with inlet gas conditions of $0.4 \mathrm{MPa}$ and $653 \mathrm{~K}$ were used, and the corresponding time evolution of the gas temperature is plotted in Figure $9 \mathrm{~b}$ for each particle diameter. This temperature profile is imposed as a boundary condition of the gas domain in the simulation. The initial temperature of the gas was extracted from Figure $9 \mathrm{~b}$ at time $t=0 \mathrm{~s}$, i.e., $402 \mathrm{~K}$. As illustrated by Figure $9 \mathrm{~b}$ and as mentioned previously, the resident time inside the nozzle of the particle depends on the particle size. Thus, heavier particles are submitted to the gas flow longer than the smallest particles. 
a)

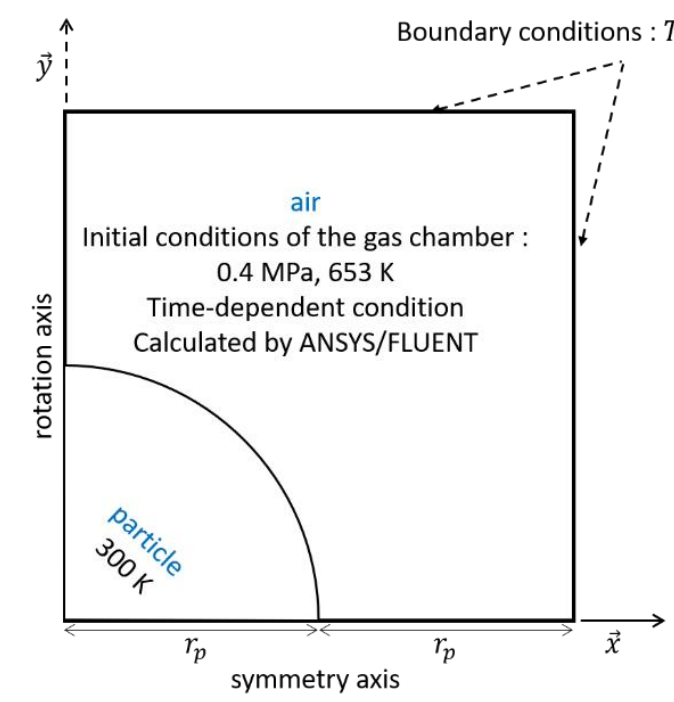

$T_{g}(t)$

b)

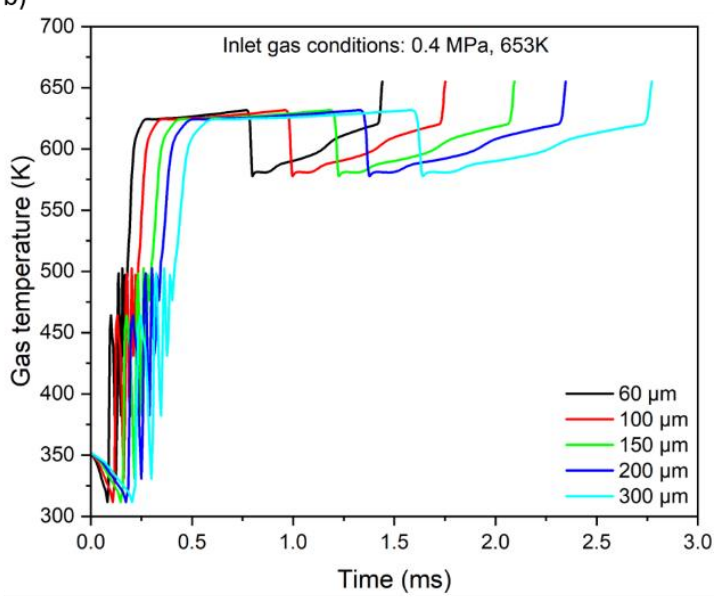

Figure 9: a) Initial and boundary conditions used to investigate the thermal gradient inside the particle (see text for details). b) Evolution of the gas temperature during the particle journey inside the cold-spray nozzle as calculated by ANSYS Fluent for different particle sizes (see text for details).

The gas (air) is assumed to act as a perfect gas, whereas the polymer's thermal properties are temperature-dependent. According to Van Krevelen and Te Nijenhuis (Van Krevelen and Te Nijenhuis, 2009), Bicerano (Bicerano, 2002), and Gee and Melia (Gee and Melia, 1970), thermal properties of polymers are highly dependent on temperature. For amorphous polymers, below and above the glass transition temperature $T_{g}$, Bicerano (Bicerano, 2002) developed some semiempirical formulae for the evolution of the specific heat and thermal conductivity. Because of the strong similarities in the temperature evolution of the thermal properties below $\mathrm{T}_{\mathrm{g}}$ for amorphous polymers, and between $\mathrm{T}_{\mathrm{g}}$ and $\mathrm{T}_{\mathrm{m}}$ (melting temperature) for crystalline polymers, we propose using the same equations while replacing $T_{g}$ with $T_{m}$. Thus, as a first approximation, the temperature dependence of the thermal conductivity $\Gamma$ is given by

$$
\Gamma(T)=\Gamma\left(\mathrm{T}_{\mathrm{m}}\right)\left(\frac{\mathrm{T}}{\mathrm{T}_{\mathrm{m}}}\right)^{0.22}
$$

and the temperature dependence of the specific heat $c_{p}$ for solid polymers is given by (Van Krevelen and Te Nijenhuis, 2009)

$$
C_{p}^{s}(T)=c_{p}(298 \mathrm{~K})\left(0.106+3 * 10^{-3} \mathrm{~T}\right) .
$$

From the evolution of the gas temperature along the entire nozzle (Figure 9b) and the particle's thermal properties (Table 2), temperature evolution of the surrounding gas by convection and temperature evolution of the particle by conduction is evaluated. Figure 10 exhibits the particle temperature profile just before its impact on the substrate. For $60-\mu \mathrm{m}$ diameter particles, the surface temperature reaches $350 \mathrm{~K}$, whereas the center temperature is $325 \mathrm{~K}$. Such a temperature gradient induces a decrease in the mechanical properties (elastic modulus and yield stress) from the particle's core to its surface. Consequently, during the high-velocity impact of the particle on the substrate, because of the thermal gradient and the mechanical properties' gradient inside the particle, different deformation mechanisms take 
place between the particle surface and core: the surface should be more deformed without excessively hindering the core mechanical properties and nascent microstructure. These effects become more critical when the thermal gradient is high.

In Figure 10b, the particle profile just before its impact on the substrate is plotted for five particle diameters: $60 \mu \mathrm{m}, 100 \mu \mathrm{m}, 150 \mu \mathrm{m}, 200 \mu \mathrm{m}$, and $300 \mu \mathrm{m}$. For larger particles $\left(r_{p}=200-300 \mu \mathrm{m}\right)$, the core temperature of the particle remains unchanged while the surface temperature rises to $15 \mathrm{~K}$. In the case of smaller particles, the whole particle is warmed, with a large temperature difference $\Delta T$ between the surface and the core. The thermal gradient between the particle core and its surface is approximately $18 \mathrm{~K}$ for a 150 - $\mu \mathrm{m}$-diameter particle and reaches $25 \mathrm{~K}$ for a 60 - $\mu \mathrm{m}$-diameter particle.
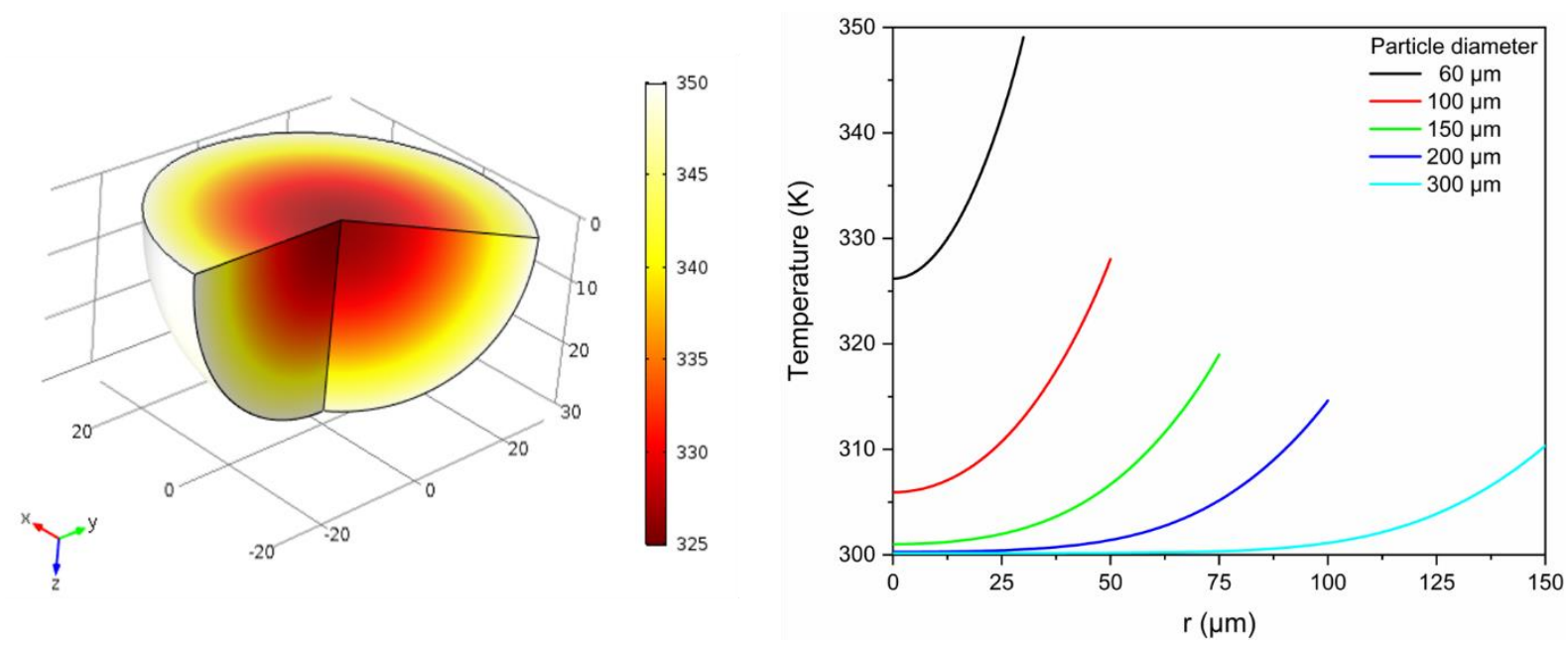

Figure 10: a) Thermal gradient of a 60- $\mu$ m-diameter particle after $1.5 \mathrm{~ms}$ (particle heating, just before impact). b) Temperature profile of several particle diameters before impact.

The particle thermal gradient can appear not that important, especially if we consider metallic or ceramic powders. However, in the case of polymers, because of their temperature dependence before the impact, the behavior of the particle has already evolved. While the yield stress of UHMWPE at room temperature is around $40 \mathrm{MPa}$, it decreases to approximately $10 \mathrm{MPa}$ at $350 \mathrm{~K}$, leading to a decrease in the yield stress of $50 \%$ at the particle surface (Brown et al., 2007). This tendency is also observed for the elastic modulus. Moreover, we must also consider that during the impact, the particle is also submitted to a gradient of strain rate ranging from a few s $\mathrm{s}^{-1}$ (top of the particle) up to $10^{5} \mathrm{~s}^{-1}$ (for the part of the particle that impacts the substrate). This range of strain rate is difficult to measure experimentally. However, the effect of the strain rate from $10^{-4} \mathrm{~s}^{-1}$ to $10^{3} \mathrm{~s}^{-1}$ is known to show a sharp increase in the elastic modulus and yield stress by approximately 200\% (Bernard et al., 2018; Brown et al., 2007; Deplancke et al., 2019). Thus, for the strain rates reached during the cold-spray process, this effect is assumed to be much more critical.

To improve our knowledge of the polymer particle's deformation behavior on the substrate during the cold-spray process, in addition to the particle velocity, the particle temperature distribution is of primary importance and should be considered, as it leads to a gradient of the mechanical properties within the particle.

\section{Conclusion}


In this study, we investigated the influence of a discontinuous nozzle on the gas flow and in-flight behavior of an isolated polymeric particle, and, in turn, its effect on the thermal particle history inside the nozzle. In the cold-spray process, not only the initial gas pressure and gas temperature but also the length and the inner shape of the nozzle, influence the coating formation. This is especially true for polymeric particles, as these materials are susceptible to strain rate and temperature.

Numerical simulations are of great help to understand the influence of discontinuities inside the nozzle on the flow field behavior and particle history before its impact on the substrate, as there is no way to directly measure the in-situ particle temperature and velocity. This allows better analysis of the influence of discontinuities inside the nozzle when additional sections are set to increase the total nozzle length. In the study case presented here, the sudden decrease in the cross-section diameter at the interface of the two nozzle induces the flow to choke once again, leading to a sharp increase in the particle's velocity. However, the sudden change in the inner section does not seem to have a significant influence on the evolution of the particle's temperature. It is interesting to note that with decreasing inlet gas pressure, the influence of the step at the discontinuity between the two nozzles decreases. Thus, for low gas pressures, the discontinuous nozzle acts as a longer continuous nozzle and contributes to the increase in the resident time of the particle inside the nozzle.

Inside the nozzle, the particles are subjected to significant thermal and velocity gradients. Because of the convection/conduction effects, particles start heating up, leading to a thermal gradient inside the particles that varies depending on its size. Because polymer behavior is strongly temperature-dependent, the thermal gradient leads to a gradient of mechanical properties along the particles' radius before the impact. Thus, the smaller the particle, the higher the thermal gradient, and the faster the effect on the substrate. These two considerations (particle temperature and velocity) influence the thermomechanical behavior and resulting deformation of the particles. Thus, knowledge of the particle temperature map is fundamental if we want to better understand and later improve the coldspray process, not only for polymers but also for metallic particles, because the temperature increase might induce some phase transformations. This analysis will be later coupled with constitutive models for polymers (Bernard et al., 2018, n.d.) to perform impact simulations of the coating formation by cold spraying.

\section{Acknowledgments}

The authors would like to acknowledge the Institute of Fluid Science at Tohoku University, which supported this research through grant J181061 under the label of the Collaborative Research Project, and LIA ELyT Global (CNRS, Université de Lyon, Tohoku University). The authors would also like to acknowledge Editage (https://www.editage.jp/) for English language editing.

\section{References}

Alhulaifi, A.S., Buck, G.A., Arbegast, W.J., 2012. Numerical and experimental investigation of cold spray gas dynamic effects for polymer coating. Journal of Thermal Spray Technology 21, 852-862.

Alkhimov, A.P., Kosarev, V., Nesterovich, N., Papyrin, A., Shushpanov, M., 1990. Device for applying coatings. Russian Patent.

ANSYS, Inc., 2017. Ansys fluent tutorial guide. ANSYS, Inc., Canonsburg, PA, USA. 
Bernard, C.A., Deplancke, T., Lame, O., Ogawa, K., Cavaillé, J.-Y., 2018. Three-dimensional constitutive model for the description of high molecular weight semicrystalline polymers over a large range of temperatures and strain rates: application to ultra-high molecular weight polyEthylene. EPJ Web of Conferences 183. https://doi.org/10.1051/epjconf/201818301016

Bernard, C.A., Lame, O., Deplancke, T., Cavaillé, J.-Y., Ogawa, K., n.d. From rheological to original threedimensional mechanical modelling of semi-crystalline polymers: application to a wide strain rate range and large deformation of ultra-high molecular weight semi-crystalline polymers. submitted to Mechanics of Materials.

Bicerano, J., 2002. Prediction of polymer properties. CRC Press.

Brown, E.N., Willms, R.B., Gray, G.T., Rae, P.J., Cady, C.M., Vecchio, K.S., Flowers, J., Martinez, M.Y., 2007. Influence of molecular conformation on the constitutive response of polyethylene: a comparison of HDPE, UHMWPE, and PEX. Experimental Mechanics 47, 381-393.

Bush, T.B., Khalkhali, Z., Champagne, V., Schmidt, D.P., Rothstein, J.P., 2017. Optimization of cold spray deposition of high-density polyethylene powders. Journal of Thermal Spray Technology 26, 1548-1564.

Cohen, N.B., 1961. Boundary-Layer Similar Solutions and Correlation Equations for Laminar HeatTransfer Distribution in Equilibrium Air at Velocities up to 41,100 Feet Per Second. National Aeronautics and Space Administration.

Deplancke, T., Fivel, M., Lame, O., 2019. 1D strain rate-dependent constitutive model of UHMWPE: from crystalline network to fibrillar structure behavior. Mechanics of Materials 137. https://doi.org/10.1016/j.mechmat.2019.103129

Deplancke, T., Lame, O., Cavaille, J.-Y., Fivel, M., Riondet, M., Franc, J.-P., 2015a. Outstanding cavitation erosion resistance of ultra high molecular weight polyethylene (UHMWPE) coatings. Wear 328, 301-308.

Deplancke, T., Lame, O., Rousset, F., Aguili, I., Seguela, R., Vigier, G., 2014. Diffusion versus cocrystallization of very long polymer chains at interfaces: experimental study of sintering of UHMWPE nascent powder. Macromolecules 47, 197-207.

Deplancke, T., Lame, O., Rousset, F., Seguela, R., Vigier, G., 2015b. Mechanisms of chain reentanglement during the sintering of UHMWPE nascent powder: effect of molecular weight. Macromolecules 48, 5328-5338. https://doi.org/10.1021/acs.macromol.5b00618

Dykhuizen, R.C., Smith, M.F., 1998. Gas dynamic principles of cold spray. Journal of Thermal Spray Technology 7, 205-212.

Engineering Toolbox, Dry Air Properties, n.d. URL https://www.engineeringtoolbox.com/dry-airproperties-d_973.html

Gee, D.R., Melia, T.P., 1970. Thermal properties of melt and solution crystallized Isotactic polypropylene. Die Makromolekulare Chemie 132, 195-201.

Jauffrès, D., Lame, O., Vigier, G., Doré, F., 2008. How nascent structure of semi-crystalline polymer powders enhances bulk mechanical properties. Macromolecules 41, 9793-9801.

Morsi, S., Alexander, A., 1972. An investigation of particle trajectories in two-phase flow systems. Journal of Fluid mechanics 55, 193-208.

Nitta, K.-H., Takayanagi, M., 1999. Role of tie molecules in the yielding deformation of isotactic polypropylene. Journal of Polymer Science Part B: Polymer Physics 37, 357-368. https://doi.org/10.1002/(SICl)1099-0488(19990215)37:4<357::AID-POLB9>3.0.CO;2-I

Popli, R., Glotin, M., Mandelkern, L., Benson, R.S., 1984. Dynamic mechanical studies of $\alpha$ and $\beta$ relaxations of polyethylenes. Journal of Polymer Science: Polymer Physics Edition 22, 407448. https://doi.org/10.1002/pol.1984.180220306

Ravi, K., Deplancke, T., Ogawa, K., Cavaillé, J.-Y., Lame, O., 2018. Understanding deposition mechanism in cold sprayed ultra high molecular weight polyethylene coatings on metals by isolated particle deposition method. Additive Manufacturing 21, 191-200. 
Ravi, K., Ichikawa, Y., Deplancke, T., Ogawa, K., Lame, O., Cavaille, J.-Y., 2015. Development of ultrahigh molecular weight polyethylene (UHMWPE) coating by cold spray technique. Journal of Thermal Spray Technology 24, 1015-1025. https://doi.org/10.1007/s11666-015-0276-5

Ravi, K., Ichikawa, Y., Ogawa, K., Deplancke, T., Lame, O., Cavaille, J.-Y., 2016. Mechanistic study and characterization of cold-sprayed ultra-high molecular weight polyethylene-nano-ceramic composite coating. Journal of Thermal Spray Technology 25, 160-169. https://doi.org/10.1007/s11666-015-0332-1

Saffman, P., 1965. The lift on a small sphere in a slow shear flow. Journal of fluid mechanics $22,385-$ 400.

Samareh, B., Dolatabadi, A., 2007. A three-dimensional analysis of the cold spray process: the effects of substrate location and shape. Journal of Thermal Spray Technology 16, 634-642.

Schmidt, T., Assadi, H., Gärtner, F., Richter, H., Stoltenhoff, T., Kreye, H., Klassen, T., 2009. From particle acceleration to impact and bonding in cold spraying. Journal of Thermal Spray Technology 18, 794.

Sulen, W.L., Ravi, K., Bernard, C., Mary, N., Ichikawa, Y., Ogawa, K., 2019. Effects of Nano-Ceramic Particle Addition for Cold Sprayed Fluoropolymer Coatings. Key Engineering Materials 813, 141-146. https://doi.org/10.4028/www.scientific.net/KEM.813.141

Takana, H., Li, H., Ogawa, K., Kuriyagawa, T., Nishiyama, H., 2010. Computational and experimental studies on cavity filling process by cold gas dynamic spray. Journal of Fluids Engineering 132, 021302.

Takana, H., Ogawa, K., Shoji, T., Nishiyama, H., 2008. Computational simulation on performance enhancement of cold gas dynamic spray processes with electrostatic assist. Journal of Fluids Engineering 130, 081701.

Van Krevelen, D.W., Te Nijenhuis, K., 2009. Properties of polymers: their correlation with chemical structure; their numerical estimation and prediction from additive group contributions. Elsevier. 